\title{
Cocoon deposition on three crab species and fish parasitism by the leech Notostomum cyclostoma from deep fjords in northern British Columbia
}

\author{
N. A. Sloan, Susan M. Bower and S. M. C. Robinson \\ Department of Fisheries and Oceans, Fisheries Research Branch, Pacific Biological Station, Nanaimo, \\ British Columbia V9R 5K6, Canada
}

\begin{abstract}
Cocoons of the sanguivorous piscicolid leech Notostomum cyclostoma (Johansson) were found on 3 crab species, Lithodes aequispina, Paralithodes camtschatica and Chionoecetes bairdi from deep fjords in the Portland Inlet system, northern British Columbia, Canada. This leech-crab association is convenient for cocoon deposition and dispersal. The leech does not appear to harm its crab hosts. Gut contents of $N$. cyclostoma collected off the crabs were fish-blood meals in various stages of digestion. The haemoflagellate Cryptobia sp. was observed in gut and proboscis area of $90 \%$ of the leeches. One leech harbored another haemoflagellate, Trypanosoma sp., in its gut. Cryptobia sp. and Trypanosoma sp. were observed in the blood of $29 \%$ of yellowfin soles Limanda aspera from one fjord. No haemoflagellates were observed in 7 other fish species caught coincidentally with the crabs. $L$. aequispina was the most cocoon - infested crab species. In Observatory Inlet, where $L$. aequispina was least common, more cocoons per crab were recorded than from the other fjords, Alice and Hastings Arms. Crabs which had not moulted for some time carried more cocoons than those with newer shells. This was less marked among $C$. bairdi subject to the exoskeleton disease of Black Mat Syndrome on older shells. The most used cocoon deposition site on crabs was the carapace, followed by the merus segments of the posterior limbs.
\end{abstract}

\section{INTRODUCTION}

Notostomum cyclostoma (Johansson) is a marine piscicolid leech recorded from the Seas of Japan and Okhotsk, Bering Sea and the Alaskan coast south to the mouth of the Stikine River (Moore and Meyer, 1951; Epshtein, 1961, 1962). Moore and Meyer (1951) reported on 161 specimens taken from soft-substrate habitats ranging from 9 to $366 \mathrm{~m}$ depth. Two leeches were found on skates, one on the red king crab Paralithodes camtschatica (Tilesius) and 158 were detached individuals. Also, cocoons of $N$. cyclostoma were found attached to single $P$. camtschatica at each of two locations. Moore and Meyer (1951) suggested from detailed anatomical observations and gut content analysis that $N$. cyclostoma was an active, free-living species which occasionally had fish-blood meals and used crab exoskeletons as cocoon 'nurseries'. On the other hand, Epshtein $(1961,1962)$ stated that $N$. cyclostoma was a 'specific parasite' of $P$. camtschatica as well as the snow crab Chionoecetes opilio (Fabricius) but he provided no evidence nor did he mention cocoon deposition.

In their review, Meyer and Barden (1955) reported that of 10 piscicolid leech-arthropod associations, only 1 , involving a shrimp host, represented a parasitic relation sensu stricto. The other 9 associations, which included Notostumum cyclostoma on crabs, were suggested as being 'nothing more than erratic attachments'. Since their review, feeding observations of piscicolid leeches have been reported on a damaged crab (Hutton and Sogandares-Bernal, 1959), from strictly circumstantial observations on an isopod species (Sawyer and White, 1969) and unequivocally on a mysid species (Burreson and Allen, 1978; Allen and Allen, 1981).

We report here on cocoon deposition by Notostomum cyclostoma on 1424 individuals including red king crabs Paralithodes camtschatica, golden king crabs Lithodes aequispina Benedict and Tanner crabs Chionoecetes bairdi Rathbun from deep fjords in northern British Columbia, Canada. N. cyclostoma is 
described as a fish- (not crab) blood feeder. Observations on the prevalence of the haemoflagellate Cryptobia sp. in gut contents of $N$. cyclostoma and on the examination of blood of coincidental fish catches are discussed.

\section{MATERIALS AND METHODS}

Fig. 1 illustrates the fjords comprising the Portland Inlet system in northern British Columbia. Each of the fjords sampled were long, narrow, deep basins isolated by sills; Alice Arm has an 18 to $25 \mathrm{~m}$ sill at its mouth, Hastings Arm has a less well defined rise to approximately $55 \mathrm{~m}$ at its mouth and Observatory Inlet has a 40 to $46 \mathrm{~m}$ sill at its south end (Pickard, 1961).

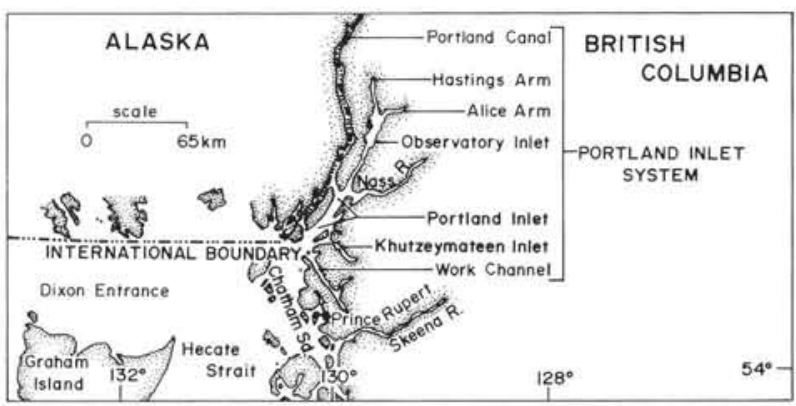

Fig. 1. Map of the north coast of British Columbia showing Portland Inlet system

As the target species was the deep-water Lithodes aequispina, individual pots were deployed along the troughs of Alice Arm, Hastings Arm and Observatory Inlet in late October- early November, 1983 and again in late February-early March, 1984. The shallow-water Paralithodes camtschatica and ubiquitous Chionoecetes bairdi were incidental by-catch. Alaskan sideentry king crab pots measuring $1.8 \times 1.8 \times 0.9 \mathrm{~m}$ with $9.0 \times 12.0 \mathrm{~cm}$ mesh were deployed to a mean fishing depth of $296 \mathrm{~m}$ (range 82 to $505 \mathrm{~m}$ ). Each pot was baited with two 21 perforated jars of frozen chopped herring. Soak times, which varied between 20.1 to $47.5 \mathrm{~h}$, were recorded along with the depth of each pot.

During both surveys, many Notostomum cyclostoma ( 70 to $110 \mathrm{~mm}$ long) and their cocoons (approximately $7.0 \mathrm{~mm}$ long and $5.5 \mathrm{~mm}$ wide) were found on crabs. A random subsample of the overall crab catch was examined during the autumn survey. Lithodes aequispina and Paralithodes camtschatica were measured for carapace length (Wallace et al., 1949) to the nearest $\mathrm{mm}$. Intact $L$. aequispina and $P$. camtschatica were weighed to the nearest $0.05 \mathrm{~kg}$. Crabs missing or regenerating limbs were not weighed. Both king crab species were rated for shell class where Class 1 had recently molted and Class 2 had older shells. Tanner crabs (Chionoecetes bairdi) were measured for carapace width (Donaldson et al., 1981) to the nearest $\mathrm{mm}$ and a subsample weighed to the nearest $0.05 \mathrm{~kg}$. Shell class was recorded according to new (1), old (2) or very old (3) (Colgate, 1982). The sex of all crabs was noted.

The locality of Notostomum cyclostoma cocoons on the carapace (dorsal/lateral), abdomen, limbs and limb segments was noted. Limbs were sampled (clockwise) in sequence always starting at the right cheliped. The position of leeches was not recorded as they were highly mobile and many had detached by the time the catch was sorted on deck.

The gut contents of leeches collected from the three fjords in both surveys were examined microscopically. Each leech was blotted dry and placed in approximately $5 \mathrm{ml}$ Hanks balanced salt solution $(\mathrm{pH} 7.0$ to 7.4). Leeches were cut in 2 approximately one third the distance from the posterior sucker, and the colour, amount and consistency of the gut contents noted. Contents were mixed on a glass slide with Hanks solution, a coverslip applied and the wet mount preparation immediately examined microscopically for flagellates. The front end of the leech was removed anterior to the clitellum, split open and the proboscis freed from the sheath. The cut surface and exposed proboscis were pressed on a slide and examined as described above.

Five leeches collected in early November were kept in $500 \mathrm{ml}$ containers of seawater at $4{ }^{\circ} \mathrm{C}$ for long-term monitoring of their gut contents. The seawater was changed every $30 \mathrm{~d}$ and on Day 105 they were examined as described above.

During both surveys blood from 58 fish (8 species), caught coincidentally with the crab trapping, was sampled by cardiac puncture using heparinized syringes. The fish samples consisted of 21 yellowfin sole Limanda aspera (Pallas), 12 spiny dogfish Squalus acanthias Linnaeus, 9 Pacific halibut Hippoglossus stenolepis (Schmidt), 6 Pacific cod Gadus macrocephalus Tilesius, 4 starry flounder Platichthys stellatus (Pallas), 4 walleye pollock Theragra chalcogramma (Pallas), 1 sablefish Anoplopoma fimbria (Pallas), and 1 Alaska skate Bathyraja sp. The blood was examined for haemoflagellates by the wet mount and/ or the modified haematocrit centrifugation technique (Bower and Margolis, 1984a).

\section{RESULTS}

\section{Characteristics of crab hosts}

The total number of each crab species examined and the range and mean of depths at which they were caught was: 789 Lithodes aequispina at 128 to $505 \mathrm{~m}$ 
$(\overline{\mathrm{x}}=310.0), 597$ Chionoecetes bairdi at 82 to $393 \mathrm{~m}$ $(\overline{\mathrm{x}}=290.4)$ and 44 Paralithodes camtschatica at 101 to $309 \mathrm{~m}(\overline{\mathrm{x}}=132.2)$. The mean carapace sizes of each species are listed according to fjord in Table 1. Between fjords, crab sizes varied little except for $L$. aequispina. Mean carapace length of Observatory Inlet L. aequispina was significantly larger (t-test; $\mathrm{p}<0.001)$, than for Alice or Hastings Arms crabs. The approximate mean live weight of the crab species was $1.44 \mathrm{~kg}$ for $L$. aequispina, $1.31 \mathrm{~kg}$ for $P$. camtschatica and $0.70 \mathrm{~kg}$ fo $C$. bairdi.

Fig. 2A illustrates an adult Notostomum cyclostoma on the carapace of Lithodes aequispina. A few specimens of a smaller fish leech, Malmiana sp., were also found on $L$. aequispina.

\section{Occurrence of Notostomum cyclostoma cocoons}

Some cocoons observed during both field trips had hatched as identified by a small hole near the cocoon edge, a few were observed in the act of hatching and the majority were intact. Time constraints, however, did not allow for cocoon ageing.

Table 1. Notostomum cyclostoma. Sizes of its 3 host crab species from Portland Inlet system, Oct/Nov, 1983

\begin{tabular}{|c|c|c|c|c|c|c|}
\hline \multirow[t]{2}{*}{ Location } & \multicolumn{2}{|c|}{$\begin{array}{l}\text { Lithodes aequispina } \\
\text { Carapace length (mm) }\end{array}$} & \multicolumn{2}{|c|}{$\begin{array}{c}\text { Paralithodes camtschatica } \\
\text { Carapace length (mm) }\end{array}$} & \multicolumn{2}{|c|}{$\begin{array}{l}\text { Chionoecetes bairdi } \\
\text { Carapace width (mm) }\end{array}$} \\
\hline & $\mathrm{n}$ & $\overline{\mathrm{x}} \pm \mathrm{SD}$ & $\mathrm{n}$ & $\overline{\mathrm{x}} \pm \mathrm{SD}$ & $\mathrm{n}$ & $\overline{\mathrm{x}} \pm \mathrm{SD}$ \\
\hline Alice Arm & 627 & $130.0 \pm 16.4$ & 37 & $120.9 \pm 16.4$ & 184 & $126.0 \pm 12.0$ \\
\hline Hastings Arm & 138 & $126.6 \pm 24.1$ & 7 & $126.1 \pm 17.8$ & 120 & $121.0 \pm 21.2$ \\
\hline Observatory Inlet & 24 & $153.3 \pm 20.2$ & - & $-\quad-$ & - & $-\quad-$ \\
\hline Total & 789 & $130.1 \pm 18.6$ & 44 & $121.7 \pm 16.5$ & $304^{\circ}$ & $130.1 \pm 17.8$ \\
\hline
\end{tabular}
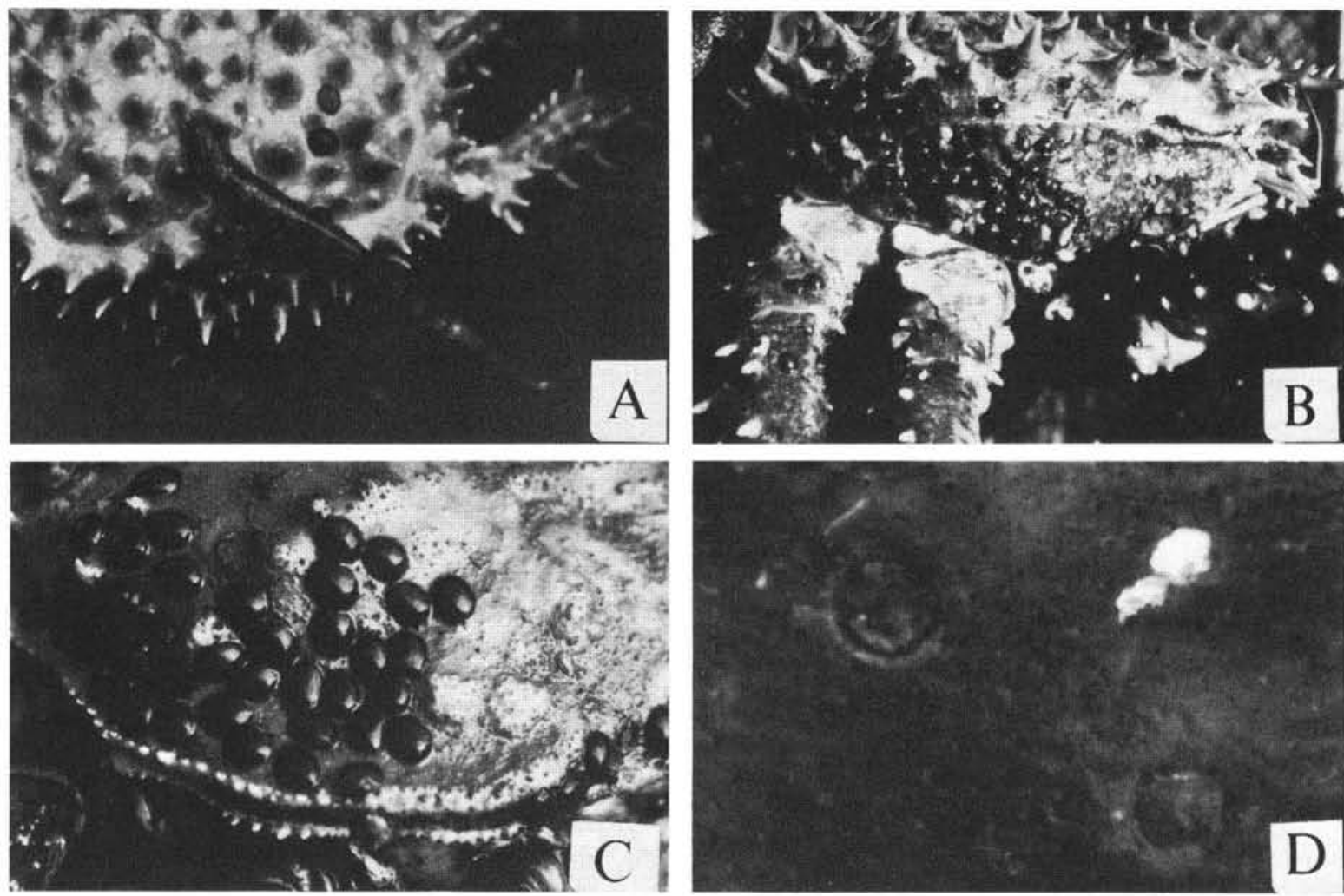

Fig. 2. Notostomum cyclostoma. (A) Individual distended with fish blood, on the carapace of Lithodes aequispina; (B) cocoons on lateral carapace surface of $L$. aequispina; (C) cocoons on dorsal carapace surface of Chionoecetes bairdi; (D) fresh feeding scar of N. cyclostoma on a halibut Hippoglossus stenolepis taken from a crab pot. Blood was oozing from upper left-hand scar. Scar diameter: ca. $7 \mathrm{~mm}$ 
Table 2. Notostomum cyclostoma. Percent occurrence of cocoons according to fjord, depth, host sex or host shell class in Portland Inlet system

\begin{tabular}{|c|c|c|c|c|c|c|}
\hline & \multicolumn{2}{|c|}{ Lithodes aequispina } & \multicolumn{2}{|c|}{ Paralithodes camtschatica } & \multicolumn{2}{|c|}{ Chinoecetes bairdi } \\
\hline & $\mathrm{n}$ & $\begin{array}{l}\% \text { with } \\
\text { cocoons }\end{array}$ & $\mathrm{n}$ & $\begin{array}{l}\% \text { with } \\
\text { cocoons }\end{array}$ & $\mathrm{n}$ & $\begin{array}{l}\% \text { with } \\
\text { cocoons }\end{array}$ \\
\hline Alice Arm & 627 & 87.9 & 37 & 21.8 & 184 & 46.2 \\
\hline Hastings Arm & 138 & 70.3 & 7 & 57.1 & 413 & 52.3 \\
\hline Observatory Inlet & 24 & 100 & 0 & - & 0 & - \\
\hline All fjords & 789 & 85.2 & 44 & 27.3 & 597 & 50.4 \\
\hline \multicolumn{7}{|l|}{ Depth range $(\mathrm{m})$} \\
\hline $101-150$ & 74 & 73.0 & 43 & 25.6 & 48 & 41.7 \\
\hline $151-200$ & 13 & 84.6 & 0 & - & 35 & 11.4 \\
\hline $201-250$ & 97 & 89.7 & 0 & - & 20 & 15.0 \\
\hline $251-300$ & 91 & 74.7 & 0 & - & 86 & 41.9 \\
\hline $301-350$ & 208 & 87.0 & 1 & 100 & 324 & 62.4 \\
\hline $351-400$ & 289 & 87.8 & 0 & - & 80 & 40.0 \\
\hline Male & 360 & 84.4 & 28 & 35.7 & 573 & 52.7 \\
\hline Female & 429 & 85.8 & 16 & 12.5 & 24 & 4.2 \\
\hline Shell Class 1 & 336 & 74.4 & 38 & 15.8 & 74 & 14.1 \\
\hline Shell Class 2 & 453 & 93.2 & 6 & 100 & 458 & 56.4 \\
\hline Shell Class 3 & - & - & - & - & 65 & 50.8 \\
\hline
\end{tabular}

Table 3. Notostomum cyclostoma. Number of cocoons per crab host species according to fjord and host shell class within Portland Inlet system

\begin{tabular}{|c|c|c|c|c|c|c|c|c|c|}
\hline \multirow{3}{*}{ Crab host } & \multirow{3}{*}{$\begin{array}{l}\text { Shell } \\
\text { class }\end{array}$} & \multicolumn{2}{|c|}{ Alice Arm } & \multicolumn{2}{|c|}{ Hastings Arm } & \multicolumn{2}{|c|}{ Observatory Inlet } & \multicolumn{2}{|c|}{ All fjords } \\
\hline & & Hosts & Cocoons & Hosts & Cocoons & Hosts & Cocoons & Hosts & Cocoons \\
\hline & & $\mathrm{n}$ & $\overline{\mathrm{x}} \pm \mathrm{SD}$ & $\mathrm{n}$ & $\bar{x} \pm S D$ & $\mathrm{n}$ & $\overline{\mathrm{x}} \pm \mathrm{SD}$ & $\mathrm{n}$ & $\overline{\mathrm{x}} \pm \mathrm{SD}$ \\
\hline Lithodes & 1 & 279 & $11.9 \pm 15.1$ & 53 & $7.3 \pm 13.1$ & 4 & $48.3 \pm 58.1$ & 336 & $11.6 \pm 16.3$ \\
\hline aequispina & 2 & 348 & $27.1 \pm 26.6$ & 85 & $28.0 \pm 36.4$ & 20 & $147.3 \pm 91.7$ & 453 & $32.6 \pm 41.9$ \\
\hline Paralithodes & 1 & 32 & $0.8 \pm 2.9$ & 6 & $2.7 \pm 3.9$ & 0 & - & 38 & $1.1 \pm 3.1$ \\
\hline camtschatica & 2 & 5 & $8.6 \pm 5.2$ & 1 & $1.0 \pm-$ & 0 & - & 6 & $7.3 \pm 5.6$ \\
\hline Chinoecetes ${ }^{\bullet}$ & 1 & 6 & $1.8 \pm 3.3$ & 65 & $0.8 \pm 2.5$ & 0 & - & 71 & $0.9 \pm 2.5$ \\
\hline bairdi & 2 & 171 & $3.5 \pm 6.3$ & 290 & $5.7 \pm 7.8$ & 0 & - & 461 & $4.9 \pm 7.4$ \\
\hline & 3 & 7 & $1.9 \pm 3.2$ & 58 & $3.9 \pm 6.0$ & 0 & - & 65 & $3.7 \pm 5.8$ \\
\hline
\end{tabular}

Table 4. Notostomum cyclostoma. Location and comparison of cocoon counts on various body areas of 789 Lithodes aequispina from Portland Inlet system

\begin{tabular}{|c|c|c|c|c|c|}
\hline \multirow[t]{2}{*}{ Body location } & \multicolumn{2}{|c|}{ No. of cocoons } & \multicolumn{3}{|c|}{$\begin{array}{l}\text { Mann-Whitney u-test comparisons of mean } \\
\text { cocoon numbers according to body area }\end{array}$} \\
\hline & $\overline{\mathrm{x}} \pm \mathrm{SD}$ & Range & Comparisons & Test statistic ${ }^{*}$ & $\mathrm{p}$ \\
\hline Carapace & $19.4 \pm 27.4$ & $0-231$ & Carapace : Limbs & $842,715.0$ & $<0.05$ \\
\hline Abdomen & $1.4 \pm 3.8$ & $0-37$ & Abdomen : Carapace & $824,534.5$ & $<0.05$ \\
\hline Limbs & $2.9 \pm 9.2$ & $0-95$ & Limbs : Abdomen & $607,550.0$ & N.S. \\
\hline Dorsal carapace & $8.9 \pm 13.1$ & $0-120$ & Dorsal : Lateral & $627,543.5$ & N.S. \\
\hline Lateral carapace & $10.5 \pm 17.7$ & $0-142$ & & & \\
\hline Anterior limbs $*$ & $0.1 \pm 0.8$ & $0-16$ & Anterior : Posterior & $527,958.5$ & $<0.01$ \\
\hline Posterior limbs $•$. & $2.8 \pm 8.7$ & $0-82$ & & & \\
\hline
\end{tabular}


The percentages of each crab species with cocoons according to fjord and depth within all fjords are given in Table 2. Lithodes aequispina was the most heavily infested species. Cocoons were found on all $104 \mathrm{~L}$. aequispina from Observatory Inlet although only 24 were examined in detail. Crabs at all depths had cocoons. Only 4 crabs (all Chionoecetes bairdi) were examined from $<101 \mathrm{~m}$ and none had cocoons. At 101 to $150 \mathrm{~m}$, where all $3 \mathrm{crab}$ species were caught in appreciable numbers, Paralithodes camtschatica had the lowest infestation. Between 401 to $505 \mathrm{~m}, 24 \mathrm{crabs}$ (all $L$. aequispina) were examined and all had cocoons. C. bairdi were found at all depths although crabs from $>400 \mathrm{~m}$ were not examined due to time constraints. Equivalent proportions of male and female $L$. aequispina had cocoons although the small sample of $P$. camtschatica yielded more infested males (Table 2). Very few female $C$. bairdi were caught as they are considerably smaller than males (Donaldson et al., 1981) and would readily escape through the pot net meshes. Few females had cocoons and all were old, shell Class 3 individuals whose exoskeletons were heavily infected with Black Mat Syndrome (Sparks and Hibbits, 1979). In all crab species older Class 2 (or 3) individuals tended to have a higher incidence of cocoons than (new) Class 1 crabs (Table 2).

The histograms in Fig. 3 illustrate the size-frequency distribution of each crab species, with corresponding mean numbers of cocoons for that size group. Larger Lithodes aequispina and Paralithodes camtschatica had more cocoons than smaller conspecifics. This trend was not demonstrated among Chionoecetes bairdi.

The mean number of cocoons per crab according to shell class of each species in each fjord is presented in Table 3. In all fjords and among all infested crab species, older shell class crabs had more attached cocoons. Lithodes aequispina tended to have many more cocoons per individual, regardless of shell class, than the other crab species. $L$. aequispina from Observatory Inlet had more cocoons per crab than conspecifics from other inlets. There was a large degree of variance in the number of cocoons per crab in all inlets.

\section{Cocoon locality on crab hosts}

Mean numbers of cocoons according to body area for Lithodes aequispina are listed in Table 4. The carapace had significantly more cocoons than the limbs or abdomen and could be densely covered (Fig. 2B). Dorsal and lateral carapace surfaces had similar numbers of cocoons. Posterior limbs had significantly more cocoons than the anterior limbs.

The most utilized locations of Notostomum cyclostoma cocoons on limbs and limb segments of Lithodes
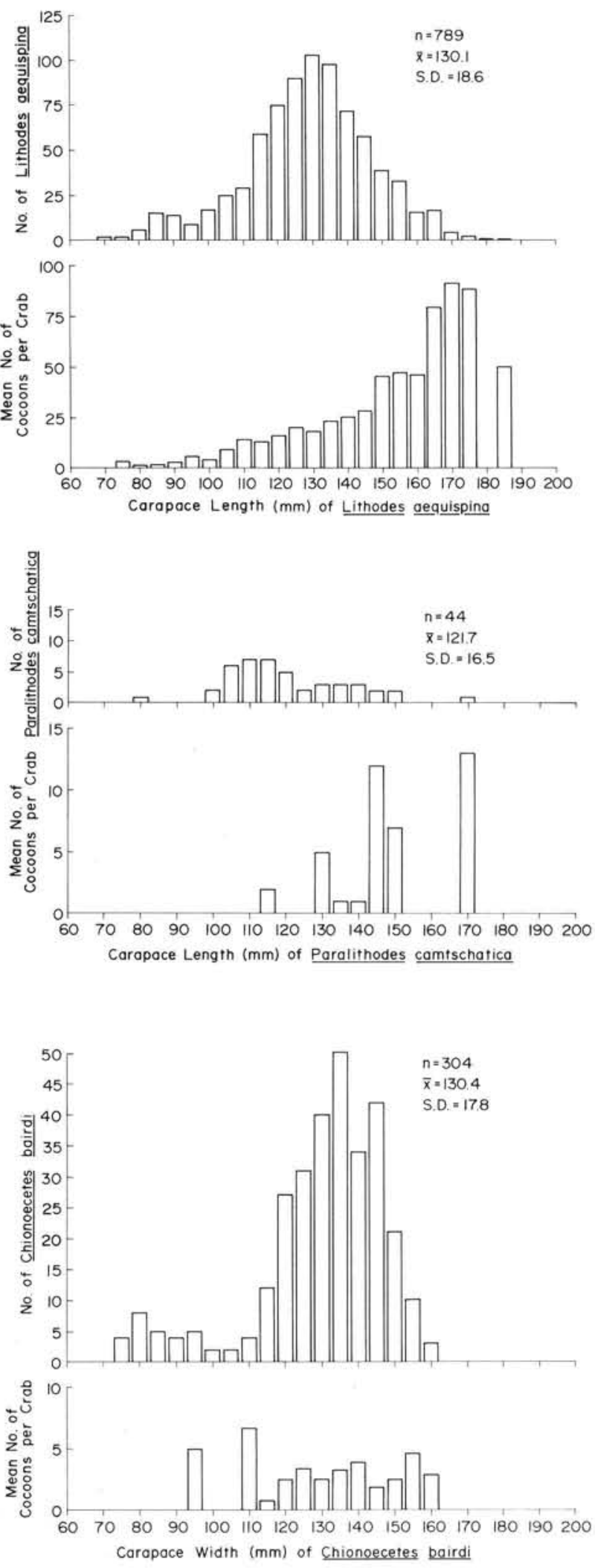

Fig. 3. Notostomum cyclostoma. Histograms of size classes of each crab species and mean number of cocoons according to each size class 
Table 5. Notostomum cyclostoma. Location of 2288 cocoons on limbs and limb segments of 789 Lithodes aequispina from Portland Inlet system

\begin{tabular}{|c|c|c|c|c|c|}
\hline & Limbs & $\begin{array}{c}\% \text { of } \\
\text { cocoons }\end{array}$ & & Segments & $\begin{array}{c}\% \text { of } \\
\text { cocoons }\end{array}$ \\
\hline \multirow{4}{*}{ Anterior } & 1 & 0.0 & \multirow[t]{2}{*}{ Proximal } & Coxa & 1.4 \\
\hline & 2 & 3.3 & & Basis & 0.0 \\
\hline & 7 & 3.2 & \multirow{6}{*}{ Distal } & Ischium & 10.0 \\
\hline & 8 & 0.0 & & Merus & 81.5 \\
\hline \multirow{4}{*}{ Posterior } & 3 & 23.3 & & Carpus & 3.4 \\
\hline & 4 & 26.6 & & Propodus & 3.7 \\
\hline & 5 & 26.8 & & Dactylus & 0.0 \\
\hline & 6 & 16.8 & & & \\
\hline
\end{tabular}

aequispina are provided in Table 5. The chelipeds (Limbs 1 and 8) had no cocoons. Most cocoons were on the 2 posterior pairs of walking legs (Limbs 3 to 6 ). The merus, the longest leg segment, was strongly favoured as a cocoon deposition site, followed by the ischium.

Of the 300 Chionoecetes bairdi with cocoons, only 3 had cocoons on the legs with the remainder being on the carapace (Fig. 2C). All leg cocoons were on the merus of the two posterior leg pairs (Legs 4, 5, 6 and 7).

\section{Observations on feeding and gut contents of Noto- stomum cyclostoma}

Adult Notostomum cyclostoma were present on crabs during both surveys. Leech guts varied from empty to sufficiently engorged with blood to distend their streamlined body shape. The gut contents of engorged leeches were usually dark red and viscous and no intact red blood cells were observed. Gut contents of leeches with small volumes tended to be equally viscous but reduced in colour as the amount diminished.

Of the 62 leeches from all fjords on both surveys, 56 $(90.3 \%)$ harboured Cryptobia sp. The haemoflagellates were found in the proboscis area as well as in gut contents. Forty four $(71.0 \%)$ of the leeches harboured heavy infections in the proboscis area. One leech, from Alice Arm in February 1984, contained many Trypanosoma sp. in its gut contents as well as in the proboscis area.

An engorged Notostomum cyclostoma was removed from the eyed side of a halibut caught in a crab pot in Observatory Inlet. Fig. 2D illustrates the fresh feeding scar and imprints of the adhesive suckers made by a $N$. cycostoma removed from this fish. No feeding scars were found on the crab hosts.

Volume and colour of the gut contents did not correlate with the number of flagellates therein, nor with the number of flagellates observed in the proboscis area. Some empty leeches had many flagellates in their guts. Two lightly coloured but distended leeches (both collected in Alice Arm, one in October and the other in February) were filled with non-viscous, brown material that contained numerous Cryptobia sp.

Two of the 5 leeches kept for $105 \mathrm{~d}$ contained a residue of their original blood meal. Four of the leeches still harboured a few Cryptobia sp. in their guts and 2 of these also had flagellates in their proboscis area.

During both surveys, the blood of 58 fish ( 8 species) was also examined for haemoflagellates which were found only in yellowfin sole Limanda aspersa. Five of 7 small ( $<200 \mathrm{~mm}$ total length) soles were infected with many Cryptobia sp, and another 1 harboured a few trypanosomes. One of 14 larger $(\geqslant 200 \mathrm{~mm}$ total length) yellowfin sole had a few Cryptobia sp. in its blood. One of the small soles was noticed to have approximately 12 small leeches (Calliobdella sp. $<10 \mathrm{~mm}$ in total length) on the fin and body surface of the blind side.

\section{DISCUSSION}

We believe the association between Notostomum cyclostoma and its crab hosts in the Portland Inlet system is one of convenience for cocoon deposition on a hard substrate (exoskeleton) and dispersion, similar to other fish leech-crab associations (Daniels and Sawyer, 1975; Kahn, 1982a, b). In habitats where firm substrates for cocoon attachment are limited, crustaceans can provide a firm, mobile alternative (Burreson and Allen, 1978). This is true for the Portland Inlet system fjords, which like other British Columbia fjords are characterised by soft sediments in their troughs (Farrow et al., 1983).

We propose that Notostomum cyclostoma do not feed on crabs. No feeding scars were seen on the exoskeletons or membranes of the crab hosts. Indeed, Meyer and Barden (1955) and Burreson and Allen (1978) concluded that substantiated reports of actual leech feeding on living arthropods were few. Neither crustaceanassociated fish leeches nor leech-like branchiobdellid oligochaetes have the oral apparatus to pierce the intact exoskeletons or membranes of arthropods (Moore and Meyer, 1951; Jennings and Gelder, 1979). The nature of the leech gut contents and presence of Cryptobia sp. support the suggestion of Moore and Meyer (1951) that N. cyclostoma feeds on fish blood. Several monogenetic Cryptobia spp. have been described from snails and planarians and from the vagina of leeches (Kozloff, 1948) but all species known from the alimentary canal of leeches are digenetic blood parasites.

The location and longevity of Cryptobia sp. in the alimentary tract of Notostomum cyclostoma, along 
with remnants of the blood meal, support the conclusion that this Cryptobia sp. is a digenetic haemoflagellate and its position in the proboscis sheath would facilitate its transmission to the next host. Thus, $N$. cyclostoma probably serves as a vector for haemoflagellates of fish in the Portland Inlet system as crabassociated fish leeches have been shown to do in the NW Atlantic (Kahn et al., 1980a, b). Three Cryptobia (= Trypanoplasma) spp. have been described from marine fish of which 2 had piscicolid leech vectors (Burreson 1979; Burreson and Zwerner 1982). Another Cryptobia spp., in Pacific salmon when in fresh water streams, also has a piscicolid leech vector (Becker and Katz 1965; Bower and Margolis 1984b).

Lithodes aequispina was more utilized as a cocoon deposition site over Chionoecetes bairdi at all depths in all fjords which may relate to host shell characteristics. The exoskeleton of $L$. aequispina has a uniform surface between the numerous, large spines which may protect adult leeches and cocoons from abrasion or host grooming. C. bairdi, on which the cocoons were less prevalent and much less abundant, had fewer and much smaller spines, thus providing less protection against abrasion. Moreover, its exoskeleton has a rough surface, perhaps making it more difficult for cocoon attachment by a large leech species such as Notostomum cyclostoma. Some shell Class 2 and all Class $3 C$. bairdi, had the exoskeleton disease Black Mat Syndrome which may also have affected their suitability for cocoon attachment. The low incidence of cocoons on Paralithodes camtschatica, which has similar exoskeleton characteristics to $L$. aequispina, could be related to its characteristically shallow-water distribution when compared to the deep-water distribution of the other species (Table 2).

In Observatory Inlet, Lithodes aequispina was relatively less common and had a $100 \%$ infestation level with many more cocoons per crab than in the other fjords (Table 3 ). In the overall crab survey the 1076 pot hours of fishing effort in Observatory Inlet yielded a catch rate of $0.09 \mathrm{~L}$. aequispina $\mathrm{h}^{-1}$ whereas 1352 pot hours in Alice Arm yielded $0.76 \mathrm{crabs} \mathrm{h}^{-1}$. Fewer crabs in Observatory Inlet perhaps limited the attachment resource, thus increasing the frequency of the attachment on what surfaces (crabs) were available.

Larger Lithodes aequispina and Paralithodes camtschatica carried more cocoons than smaller crabs, which demonstrates an opportunistic response of Notostomum cyclostoma to resource quantity (crab size). Chionoecetes bairdi was smaller, with less surface area than $L$. aequispina and would be expected to carry fewer cocoons. Among male $C$. bairdi, host size was less important to cocoon number although females, being much smaller than males (Donaldson et al., 1981) carried fewer cocoons.
Number of cocoons deposited increased with duration of host surface availability (shell age) for all host species. Time constraints did not allow us to assess cocoon viability on the host species but an appreciable proportion of the cocoons on older shell class crabs were perforated with single, small holes signifying that the leeches had hatched. Very old-shelled crabs often had damaged cocoons. Up to $70 \%$ of Johanssonia arctica (Johansson) cocoons on old-shelled Chionoecetes opilio were empty (Kahn, 1982b). Kahn (1982a) proposed that cocoons of $J$. arctica may not last longer than $1 \mathrm{yr}$ on crab hosts. Cocoon numbers increased greatly between shell Class 1 and 2 C. bairdi, but decreased between Class 2 and 3 individuals, perhaps because of Black Mat Syndrome. Kahn (1982a, b) found more sanguivorous fish leeches, $J$. arctica, and their viable cocoons on younger shell class $C$. opilio than older shell class individuals.

The carapace surface were strongly preferred over the abdomen and limbs of Lithodes aequispina and Chionoecetes bairdi, neither of which can groom the carapace directly. The abdomen and limbs of $L$. aequispina could be expected to encounter more abrasion and the anterior limbs subject to more grooming than posterior limbs. The cocoon concentration on the merus segment of the periopods could relate to both the large size of the segment and the proximal position of the merus in relation to total leg length, which could aid in reducing abrasion and cheliped grooming. Daniels and Sawyer (1975) also found fish leech Myzobdella lugubris Leidy cocoons on the posterolateral carapace of the swimming crab Callinectes sapidus Rathburn.

Cocoons were rare on the limbs of Chionoecetes bairdi except for a few on the merus. This differs markedly from Kahn's (1982a, b) reports of Johanssonia arctica cocoons which were almost always found on the ventral distal merus surface of the anterior pereiopods of $C$. opilio and rarely on the carapace. Up to $1246 \mathrm{~J}$. arctica cocoons could be found on the merus segments of a host crab. According to Meyer and Kahn (1979) the characteristic cocoon sizes of $J$. arctica are $1.5 \mathrm{~mm}$ long $\times 1.0 \mathrm{~mm}$ wide and the leech body length averaged $21.5 \mathrm{~mm}$. These are considerably smaller than the cocoon sizes and body lengths of Notostomum cyclostoma. Smaller cocoons and adults of J. arctica are probably less susceptible to disturbance by the activities of their crab host than N. cyclostoma and its crab hosts.

Acknowledgements. We thank S. C. Jewett of North Pacific Research for field assistance and L. Mackie for drafting the figures. J. Madill (National Museum of the Natural Sciences, Ottawa) identified the leeches. Drs. G. S: Jamieson and Z. Kabata and 2 anonymous reviewers provided valuable comments. 


\section{LITERATURE CITED}

Alen, D. M., Allen, W. B., (1981). Seasonal dynamics of a leech-mysid shrimp interaction in a temperate salt marsh. Biol. Bull, mar. biol. Lab., Woods Hole 160: 1-10

Becker, C. D., Katz, M. (1965). Infections of the hemoflagellate, Cryptobia salmositica Katz, 1951, in freshwater teleosts of the Pacific Coast. Trans. Am. Fish. Soc. 94: 327-333

Bower, S. M., Margolis, L. (1984a). Detection of infection and susceptibility of different Pacific salmon stocks (Oncorhynchus spp.) to the haemoflagellate Cryptobia salmositica. J. Parasitol. (in press)

Bower, S. M., Margolis, L. (1984b). The distribution of the haemoflagellate Cryptobia salmositica in British Columbia and the Yukon Territory and the seasonal pattern of infection in a coastal river. Can. J. Zool. (in press)

Burreson, E. M. (1979). Structure and life cycle of Trypanoplasma beckeri sp. n. (Kinetoplastida), a parasite of the Cabezon, Scorpaenichthys marmoratus, in Oregon coastal waters. J. Protozool. 26: 343-347

Burreson, E. M., Allen, D. N. (1978). Morphology and biology of Mysidobdella borealis (Johansson) comb. $n$. (Hirudinea: Piscicolidae), from mysids in the western North Atlantic. J. Parasitol. 64: 1081-1091

Burreson, E. M., Zwerner, D. E. (1982). The role of host biology, vector biology, and temperature in the distribution of Trypanoplasma bullocki infections in the lower Chesapeake Bay. J. Parasitol. 68: 306-313

Colgate, W. A. (1982). Some problems in assessing the Tanner crab, Chionoecetes bairdi, population in the Gulf of Alaska and one possible remedy. Alaska Sea Grant Rept. 82-10: 617-634

Daniels, B. A., Sawyer, R. T. (1975). The biology of the leech Myzobdella lugubris infesting blue crabs and catfish. Biol. Bull. mar. biol. Lab., Woods Hole 148: 193-198

Donaldson, W. E., Cooney, R. T., Hillsinger, J. R. (1981). Growth, age, and size at sexual maturity of Tanner crab, Chionoecetes bairdi, M. J. Rathbun, in the northern Gulf of Alaska (Decapoda, Brachyura). Crustaceana 40: 286-302

Epshtein, V. M. (1961). A review of the fish leeches (Hirudinea: Piscicolidae) from the northern seas of USSR. Proc. Acad. Sci. USSR 141: 1121-1124

Epshtein, V. M. (1962). A survey of fish leeches (Hirudinea: Piscicolidae) from the Bering and Okhotsk Seas and from the Sea of Japan. Proc. Acad. Sci. USSR 144: 648-651

Farrow, G. E., Syvitski, J. P. N., Tunnicliffe, V. (1983). Suspended particlate loading on the macrobenthos in a highly turbid fjord: Knight Inlet, British Columbia. Can. J. Fish. aquat. Sci. 40 (Supp. 1): 273-288

Hutton, R. F., Sogandares-Bernal, F. (1959). Notes on the distribution of the leech, Myzobdella lugubris Leidg, and its association with mortalities of the blue crab, Callinectes sapidus Rathbun. J. Parasitol. 45: 384, 404

Jennings, J. B., Gelder, S. R. (1979). Gut structure, feeding and digestion in the branchiobdellid oligochaete Cambrincola macrodonta Ellis 1912, an ectosymbiote of the freshwater crayfish Procambarus clarkii. Biol. Bull. mar. biol. Lab., Woods Hole 156: 300-314

Khan, R. A. (1982a). Biology of the marine piscicolid leech Johanssonia arctica (Johansson) from Newfoundland. Proc. helminth. Soc. Wash. 49: 266-278

Kahn, R. A. (1982b). Biology of a leech ectocommensal on the spider crab, Chionoecetes opilio. Alaska Sea Grant Rept 82-10: 681-694

Khan, R. A., Barrett, M., Murphy, J. (1980a). Blood parasites of fish from the northwestern Atlantic Ocean. Can. J. Zool. 58: 770-781

Khan, R. A., Murphy, J., Taylor, D. (1980b). Prevalence of a trypanosome in Atlantic cod (Gadus morhua) especially in relation to stocks in the Newfoundland area. Can. J. Fish. aquat. Sci. 37: 1467-1475

Kozloff, E. N. (1948). The morphology of Cryptobia helicis Leidy, with an account of the fate of the extranuclear organelles in division. J. Morph. 83: 253-279

Meyer, M. C., Barden, A. A. (1955). Leeches symbiotic on Arthropoda, especially decapod crustacea. Wasmann J. Biol. 13: 297-311

Meyer, M. C., Khan, R. A. (1979). Taxonomy, biology, and occurrence of some marine leeches in Newfoundland waters. Proc. helminth. Soc. Wash. 46: 254-264

Moore, J. P., Meyer, M. C. (1951). Leeches (Hirudinae) from Alaskan and adjacent waters. Wasmann J. Biol. 9: 11-17

Pickard, G. L. (1961). Oceanographic features of inlets in the British Columbia mainland coast. J. Fish. Res. Bd Can. 18: 907-999

Sawyer, R. T., White, M. G. (1969). A new genus and species of marine leech, Glyptontobdella antarctica, from an Antarctic isopod. Br. Antarct. Surv. Bull. 22: 1-14

Sparks, A. K., Hibbits, J. (1979). Black Mat Syndrome, an invasive mycotic disease of the tanner crab, Chionoecetes bairdi. J. Invert. Pathol. 34: 184-191

Wallace, M. M., Pertuit, C. J., Hvatum, A. R. (1949). Contribution to the biology of the king crab (Paralithodes camtschatica Tilesius). U.S. Fish. Wildl. Serv. Fish. Leafl. 340: $1-50$ 